\title{
Guest editorial The International Successful School Principalship Project: reflections and possibilities
}

\section{Rationale}

Large, sustained, multi-nation and collaborative research networks are becoming more popular because of their power to produce findings that generalise across contexts and provide contextually nuanced views of a phenomenon (Day and Gurr, 2018). There have been four major projects of this type in educational leadership since the beginning of this century: The International Successful School Principalship Project (ISSPP); the International Study of the Preparation of Principals; Leadership for Learning and the International School Leadership Development (Gurr et al., 2020). Whilst there are other projects emerging (Gurr et al, 2021), the ISSPP has the broadest scope and is by far the most comprehensive. The other projects focussed on aspects of school leadership such as leadership preparation, leadership for learning and leading in challenging contexts. Caldwell (2014, p. 22) suggested that the ISSPP "is the most comprehensive and coherent international comparative study of the principalship ever undertaken." The ISSPP now has research groups in more than 20 countries. It has contributed more than 200 complex case studies and more than 300 journal papers, book chapters and books.

The initial purpose of the ISSPP was to explore, through multiple perspective case studies, the characteristics, qualities and practices of principals leading successful schools and how others contribute to school success. Since the ISSPP began in 2001, three strands have developed:

Strand 1. This explored the work of successful principals through multiple-perspective case studies. Some schools were re-visited five years later to explore the sustainability of success.

Strand 2. This strand considered the work of principals in visible and invisible underperforming schools.

Strand 3. This strand explored the identity formation of principals leading successful schools and did so through individual interviews.

To date, the ISSPP has not relied upon theoretical positions to drive the research. The core methodology relies on extensive multiple-perspective case studies using individual and group interviews (principals, council members, teachers, students and parents), observation, document collection and, in some cases, surveys to better understand principal leadership of successful schools. Whilst it has not relied on theoretical positions, it has, of course, been driven by observations of the strengths and limitations of previous research. At ISSPP's inception two decades ago, research on principals relied on self-reports and/or limited engagement with the work of principals, and much of the educational leadership literature at this time came from the United States and the United Kingdom. Researchers were challenged to answer "how" and "why" questions. Day et al. (2000) saw that one way to overcome this was through more extensive case-based studies that involved a variety of perspectives collected through several research methods. Their study of successful headteachers in England was the stimulus for

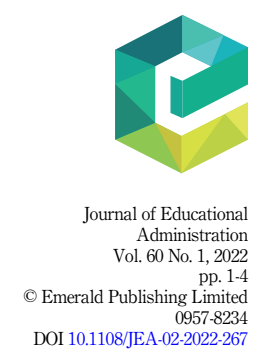


JEA

60,1

creating the ISSPP and the research model for how the ISSPP research would proceed. The ISSPP addressed the narrowness of the research base through the inclusion of other countries, which, over time, has seen research groups in all continents. Early research also focussed on school effectiveness (with an emphasis on quantitative methods) rather than school success; success is a broader conception of the impact of schools and requires more engaged research methods. The lack of engagement with theoretical positions is a legitimate criticism of the ISSPP (e.g. Eacott, 2018) and will likely be addressed in the next iteration of the project. When writing this editorial in 2021, the ISSPP is developing a complexity/system conceptual framework to guide the project's future development. The project has provided supporting evidence for important ideas (the four-frame leadership view of Leithwood and colleagues; e.g. Day and Leithwood, 2007; Ylimaki and Jacobson, 2011) and has generated several leadership models (see Gurr, 2015). It has also generated cross-country comparative information to provide a discussion of the importance of context (e.g. the four ISSPP project books: Day and Leithwood, 2007; Day and Gurr, 2014; Moos et al., 2011; Ylimaki and Jacobson, 2011), and yet, it has arrived at several important general statements on educational leadership that seem to transcend context (see Gurr and Day, 2014). A final concern was a need for research that engaged deeply with principal and school leadership and yet was substantial enough to make substantive claims. Research that relies on small numbers of case studies often produces detailed understandings about a phenomenon. Still, these studies struggle to contribute in a cumulate way to knowledge building because of their small scale and lack of connectedness with other research (Leithwood, 2005). Case study research on a large scale, like the ISSPP, promises more trustworthy and richer findings and to have both the high internal validity of intensive qualitative research and the high external validity of large-scale quantitative research (Leithwood, 2005).

This special issue intends to capture some of the rich corpus of research produced by the ISSPP over the past two decades. This special issue explores the work of the ISSPP through papers that reflect upon and critique the research and others that showcase the country's knowledge produced in Cyprus, Israel, Spain, Mexico, the United States and Sweden. It is a celebration and reflection of a 20 -year research program. It provides examples of the rich information generated and reflects on what has been achieved, what has not been achieved and future developments.

The issue is divided into project commentary and synthesis, country reports and special issue commentary. The first section of the two papers provides critical and reflective commentary and project synthesis.

The first paper, by Gunnulfsen, Jensen and Møller, is a critical reflection across all three strands and is provided by one of the founding research groups from the University of Oslo. Møller was a founding member of the project, with Gunnulfsen and Jensen involved more recently. The paper provides a critical perspective from the Norwegian group and is not necessarily agreed upon by all members of the project (see Day's commentary later in the paper).

The second paper is by founding members of the Australian group, Gurr, Drysdale and Goode. It focuses on the description of 13 models that have already been published and the construction of a new model-an open systems model of successful school leadership. The paper serves two purposes-to document the many models that the ISSPP groups have produced and to produce a new model that captures these pieces of knowledge. The 38 multiple-perspective case studies of successful principals that form the basis of the models come from two states of Australia (Tasmania and Victoria), Cyprus, Indonesia and Singapore. In addition, ISSPP survey research from Tasmania is included in one of the models. The authors see the new model as a starting point to build and refine future models that can be tested with quantitative data.

The second section includes papers that engage deeply with the knowledge generated in five countries: Cyprus, Israel, Spain, Mexico and the United States. All of these country-based reports report on research that has been done as part of the ISSPP, meaning the findings reported have been generated from multiple perspective case studies of successful principals. 
This section begins with Pashiardis and Kafa reporting on 11 cases from Cyprus. The Cyprus cases see successful principals as those who have been able to negotiate the internal and external environments of the school. From the analysis of these cases, they arrive at a successful school leadership model that describes three areas of leadership action: developing external relations and networking with all relevant actors; promoting a collaborative and shared ownership feeling among their members and within school organisation, and promoting a clear vision and endorsing a specific values system.

In the following paper, Tubin and Farchi report on 21 cases from Israel. Straddling strands one and two, the cases included successful, coasting, failing and low-performing schools. The cases also distinguish between the practices of successful and less successful principals. A successful school and principal model has three elements: organisational restructuring affects behaviour; behaviour establishes priorities and values; values facilitate environmental and legitimacy support. While the schematic simply connects the three elements in a circle, it has considerable complexity within each element. The principal model is used to present the point of intervention for successful principals.

The focus then switches to Spain with a review by Moral Santaella of the 12 Spanish ISSPP cases from researchers at the University of Granada, the Autonomous University of Madrid and the University of Huelva. These cases covered strands 1 to 3 and demonstrated the strong social justice orientation of the principals and the use of several leadership processes (transformation, instructional and collaborative leadership) to achieve excellence through a focus on equity.

The next article, from Torres-Arcadia, Nava-Lara, Rodríguez-Uribe and GlassermanMorales, explores the substantial corpus of ISSPP research in Mexico, covering 14 cases and reported in five journal articles, five conference papers and four books. A nested model is constructed that begins with principal socio-emotional skills, then moves through school organisation adapted to the context and the available resources, continuous improvement of teaching and principalship practices based on student needs, educational materials and methods adapted to the students' needs, and which ends with worthy educational infrastructure. The principal is shown to be centrally important to school success. The authors state that successful school leadership "is a process performance by the person who has the post and who has decided to use the available resources and carry out the necessary tasks, meeting the needs and enhancing the capabilities of their collaborators".

The final country report is from several research groups from the USA. Ylimaki, Jacobson, Johnson, Klar, Nino, Orr and Scribner report on 23 cases, from across Buffalo, Massachusetts, Texas, Indiana, Arizona, South Carolina and New York City, and involving 30 researchers. Support for Leithwood's (2005) four-element view of educational leadership came from the early studies (and confirmed in other ISSPP studies), and, given the length of time of the ISSPP, the USA cases were able to explore changes that have happened over the past two decades: sociocultural effects, culturally responsive leadership and the importance of understanding leadership identity. Contextual differences were also shown. For example, the school's sustainability and principal success found in other research groups (e.g. Goode's research in Melbourne, Australia; Goode, 2017) was not as evident in those cases in the USA that were revisited. Looking forward, the USA cases bring to the fore the need to focus on diversity and equity issues as the global demographic shifts change the student population.

The special issue concludes with important commentary pieces by the founder of the ISSPP, Day, and Johansson and Ärlestig, who are from one of the original country groups, Sweden. These commentaries reinforce the considerable contribution of the ISSPP and indicate that ongoing work and future possibilities in the project's third decade.

The ISSPP is at an exciting stage. With 20 years of international research, it is the most sustained and extensive educational leadership research project ever. Currently, there is a major review underway of the research corpus of the ISSPP, major revisions to the research protocols 
JEA

60,1

to include foci on middle leaders, governance and improvement of teaching and learning, framing of the research using complexity and system thinking views, development of an analytical framework which is very close to the several models reported by Gurr, Drysdale and Goode, and development of a teacher survey to be used in future multiple perspective case studies. The move away from a dominant focus on principals is essential. It does not negate the considerable influence of principals. Still, it does acknowledge the increasingly collaborative nature of schools and the leadership influence of many in schools-in time. There is likely going to be a need also to include teacher and student leadership. The special issue provides time for pause and reflection on some of the considerable achievements of the project.

David Gurr

The University of Melbourne, Melbourne, Australia, and

Peter Moyi

University of South Carolina, Columbia, South Carolina, USA

\section{References}

Caldwell, B.J. (2014), "Forward", in Day, C. and Gurr, D. (Eds), Leading Schools Successfully: Stories from the Field, Routledge, London, pp. 21-22.

Day, C. and Gurr, D. (Eds), (2014), Leading Schools Successfully: Stories from the Field, Routledge, London, UK.

Day, C. and Gurr, D. (2018), "International networks as sites for research on successful school leadership", in Lochmiller, C. (Ed.), Complementary Research Methods in Educational Leadership and Policy Studies, Palgrave MacMillan, New York, NY, pp. 341-357.

Day, C. and Leithwood, K. (Eds), (2007), Successful Principal Leadership in Times of Change: an International Perspective, Springer-Kluwer, Dordrecht, The Netherlands.

Day, C., Harris, A., Hadfield, M., Tolley, H. and Beresford, J. (2000), Leading Schools in Times of Change, Open University Press, Buckingham, UK.

Eacott, S. (2018), Beyond Leadership: A Relational Approach to Organizational Theory in Education, Springer Nature, Singapore.

Goode, H. (2017), A Study of Successful Principal Leadership: Moving from Success to Sustainability, Doctor of Philosophy Thesis, The University of Melbourne.

Gurr, D. and Day, C. (2014), "Thinking about leading schools", in Day, C. and Gurr, D. (Eds), Leading Schools Successfully: Stories from the Field, Routledge, London, UK, pp. 194-208.

Gurr, D., Drysdale, L. and Goode, H. (2020), "Global research on principal leadership", in Nobit, G.W. (Ed.), The Oxford Research Encyclopedia of Educational Administration, Oxford University Press, NY, NY.

Gurr, D., Drysdale, L. and Goode, H. (2021), "International educational leadership projects", in Barnett, B. and Woods, P. (Eds), Educational Leadership for Social Justice and Improving High-Needs Schools: Findings from 10 Years of International Collaboration, Information Age Publishing, Charlotte: NC, pp. 13-29.

Leithwood, K. (2005), "Understanding successful principal leadership: progress on a broken front", Journal of Educational Administration, Vol. 43 No. 6, pp. 619-629.

Moos, L., Johansson, O. and Day, C. (Eds), (2011), How School Principals Sustain Success over Time. International Perspectives, Springer-Kluwer, Dordrecht, The Netherlands.

Ylimaki, R. and Jacobson, S. (Eds), (2011), US and Cross-National Policies, Practices and Preparation: Implications for Successful Instructional Leadership, Organizational Learning, and Culturally Responsive Practices, Springer-Kluwer, Dordrecht. 